\title{
A Novel Mouse Model of Staphylococcus aureus Vascular Graft Infection
}

\section{Noninvasive Imaging of Biofilm Development in Vivo}

\author{
Hélène Van de Vyver, ${ }^{*}$ Philipp R. Bovenkamp, ${ }^{\dagger}$ Verena Hoerr, ${ }^{\dagger \ddagger}$ Katrin Schwegmann, ${ }^{\S}$ Lorena Tuchscherr, ${ }^{\ddagger}$ Silke Niemann, ${ }^{*}$ \\ Laura Kursawe, "Christina Grosse, ${ }^{* *}$ Annette Moter, "Uwe Hansen, ${ }^{\dagger \dagger}$ Ute Neugebauer, ${ }_{* *+\ddagger}$ Michael T. Kuhlmann, \\ Georg Peters, * ${ }^{\|\|}$Sven Hermann, ${ }^{\S}$ and Bettina Löffler ${ }^{\ddagger}$
}

\begin{abstract}
From the Institute of Medical Microbiology, * the Department of Clinical Radiology, ${ }^{\dagger}$ the Institute of Experimental Musculoskeletal Medicine, ${ }^{\dagger \dagger}$ and the European Institute for Molecular Imaging, ${ }^{\S}$ University Hospital Muenster, Muenster; the Institute of Medical Microbiology $y^{\ddagger}$ and the Center for Sepsis Control and Care," Jena University Hospital, Jena; the Biofilmcenter, "German Heart Institute Berlin, Berlin; the Leibniz Institute of Photonic Technology, ** Jena; the Institute of Physical Chemistry, ${ }^{\ddagger \ddagger}$ University of Jena, Jena; and Cells-in-Motion Cluster of Excellence (EXC 1003 - CiM), ${ }^{\| I}$ University of Münster, Münster, Germany
\end{abstract}

\author{
Accepted for publication \\ October 4, 2016. \\ Address correspondence to \\ Hélène Van de Vyver, M.Sc., \\ Institute of Medical \\ Microbiology, University \\ Hospital Münster, \\ Domagkstraße 10, 48149 \\ Münster, Germany. E-mail: \\ helene.vandevyver@uni- \\ muenster.de.
}

\begin{abstract}
Staphylococcus aureus causes very serious infections of vascular grafts. Knowledge of the molecular mechanisms of this disease is largely lacking because of the absence of representable models. Therefore, the aim of this study was to set up a mouse model of vascular graft infections that closely mimics the human situation. A catheter was inserted into the right carotid artery of mice, which acted as a vascular graft. Mice were infected i.v. using 8 different S. aureus strains, and development of the infection was followed up. Although all strains had varying abilities to form biofilm in vitro and different levels of virulence in mice, they all caused biofilm formation on the grafts. This graft infection was monitored using magnetic resonance imaging (MRI) and ${ }^{18} \mathrm{~F}$ fluordeoxyglucose positron emission tomography (FDG-PET). MRI allowed the quantification of blood flow through the arteries, which was decreased in the catheter after infection. FDG-PET revealed high inflammation levels at the site of the catheter after infection. This model closely resembles the situation in patients, which is characterized by a tight interplay between pathogen and host, and can therefore be used for the testing of novel treatment, diagnosis, and prevention strategies. In addition, combining MRI and PET with microscopic techniques provides an appropriate way to characterize the course of these infections and to precisely analyze biofilm development. (Am J Pathol 2017, 187: 268-279; http://dx.doi.org/10.1016/j.ajpath.2016.10.005)
\end{abstract}

With the increasing prevalence of cardiovascular diseases, the application of vascular grafts has increased substantially during the last decade. However, these vascular grafts do not come without complications because they are accompanied with a $1 \%$ to $6 \%$ chance of infection. ${ }^{1-4}$ These infections are associated with mortality rates of $>20 \%$, making them very serious complications. ${ }^{1}$ Staphylococcus aureus is one of the leading causative agents because it readily adheres to the surface of the implanted device and forms thick biofilm layers. These biofilm layers are difficult to detect because they are often unaccompanied by clinical symptoms and are almost impossible to eradicate, even with long-term antibiotic treatment. ${ }^{5,6}$ Within these biofilms the bacteria are protected from host immune responses and antibiotic treatment, using multifactorial mechanisms that are not yet completely unraveled. The clinical consequence

\footnotetext{
Supported by a fellowship of the Graduate School of the Cells-in-Motion Cluster of Excellence (EXC 1003 - CiM), University of Münster, Germany (H.V.d.V.); projects A10, C6, and Z2 from the Deutsche Forschungsgemeinschaft, Collaborative Research Center SFB 656 Cardiovascular Molecular Imaging; the Interdisciplinary Centre of Clinical Research (IZKF Muenster, Core Unit PIX); and grant CSCC FKZ $01 E 01502$ from the Federal Ministry of Education and Research through the Center for Sepsis Control and Care.

S.H. and B.L. contributed equally to this work.

Disclosures: None declared.
} 
is that antibiotic levels up to 1000 times higher than for planktonic bacteria are necessary and these concentrations are not clinically feasible. ${ }^{7-10}$ Much research is being performed to discover ways to prevent the bacteria from adhering to the surface in the first place or to find better delivery methods that would enable antibiotics to eradicate the bacteria hidden in biofilm. ${ }^{11-16}$ However, progress has been limited, not least because of the lack of adequate in vivo models. Because these biofilms form a prime source for chronic recurrent infections and there is no curative treatment, the implanted device usually needs to be surgically removed, which involves additional invasive interventions for the patient and high costs for the health care system.

Thus, it is of high importance to understand the underlying pathogenesis of biofilm formation on vascular grafts within the whole organism to find quick and effective treatment possibilities without having to resort to invasive procedures. To achieve this, it is necessary to have a representative animal model that closely reflects the longterm process of biofilm formation in vivo.

Many in vitro models have been set up to study biofilm formation. These models have provided useful information on the genes necessary for biofilm formation and the mechanisms by which a biofilm is maintained. ${ }^{9,17-20}$ However, they do not cover the factors that play a role during biofilm formation with regard to the host-pathogen interactions. Within the whole organism the bacteria pass different pathogenic steps, including survival during bacteremia, adherence, and biofilm maturation on foreign material under continuous stress from the host immune system. ${ }^{21}$ S. aureus has a complex regulatory network that helps the bacteria cope with stress conditions and also influence the process of biofilm formation. ${ }^{22}$ Therefore, it is necessary to study biofilm formation in vivo from the initial steps until maturity to detect all virulence and regulatory factors involved in this process. Studies on biofilm in human samples provided first indications that a mature biofilm is built up in complex layers. ${ }^{23}$ The nature and effect of the biofilm structure formed in vivo are only marginally understood but might have important implications for diagnostics and therapeutic interventions. Up to now the in vivo study of biofilm formation on vascular grafts has mostly been limited to rat models in which the graft is placed subcutaneously and topically infected there. ${ }^{24-26}$ Although these are straightforward, high-throughput models, they do not accurately represent the dynamic and complex structure of vascular biofilm formation. Some researchers have set up models in dogs and pigs, where the grafts are placed intravascularly to closely mimic the situation in patients. ${ }^{27-30}$ However, such an intravascular graft model is still missing in the mouse, offering a highthroughput, cost-effective alternative, having the additional benefit of allowing the use of genetically manipulated, humanized mice. ${ }^{31}$

Therefore, the aim of this study was to create a mouse model to realistically study the complex process of biofilm formation on vascular grafts in vivo. This model is based on a polytetrafluoroethylene (PTFE) catheter, a polymer material often used for vascular grafts, ${ }^{32}$ placed intravascularly into the right carotid artery (RCA). After recovery from the surgical intervention, animals are systemically infected via the tail vein. Therefore, bacteria were delivered to the catheter via the bloodstream. In addition, to minimize the amount of mice necessary for research and to develop a long-term infection model during several weeks, we followed up the infection noninvasively by positron emission tomography using F18-fluordeoxyglucose (FDG-PET) and magnetic resonance imaging (MRI).

\section{Materials and Methods}

\section{Bacterial Isolates and Inoculum}

For the setup of the infection model, the bacterial strain S. aureus LS1 was used. LS1 is a murine arthritis isolate that has been used in infection models before. ${ }^{33}$ Furthermore, 26 $S$. aureus strains were collected from patients with vascular infections from the University Hospital in Muenster, Germany, and 33 S. aureus strains were obtained from the nasal swabs of healthy individuals.

\section{In Vitro Biofilm Assay}

All collected $S$. aureus strains were tested for their ability to form biofilm in vitro. The strains Staphylococcus carnosus TM300 and Staphylococcus epidermidis RP62A were used as negative and positive controls, respectively. Bacteria were grown overnight at $37^{\circ} \mathrm{C}$ in tryptic soy broth plus $0.25 \%$ glucose and diluted 1:200 in tryptic soy broth plus $0.25 \%$ glucose. Then $200 \mu \mathrm{L}$ of each strain was inoculated in duplicates into sterile 96-well polystyrene microtiter plates (Greiner, Pleidelsheim, Germany). The plates were incubated for 24 hours at $37^{\circ} \mathrm{C}$. The wells were washed twice with $200 \mu \mathrm{L}$ of sterile phosphate-buffered saline (PBS) after which they were incubated for 15 minutes at room temperature with $100 \mu \mathrm{L}$ of $1 \%$ crystal violet. This was washed three times with $200 \mu \mathrm{L}$ of PBS, after which $100 \mu \mathrm{L}$ of an ethanol/aceton (80:20) solution was added to each well and incubated at room temperature until the biofilm was completely resuspended. The absorbance was measured with a Biorad iMark Microplate reader (Bio-Rad Laboratories, Hercules, CA) at $655 \mathrm{~nm}$.

\section{In Vivo Vascular Graft Model in Mice}

CD1 mice were bred and housed in microisolator cages and were fed food and water ad libitum. When they reached 10 to 14 weeks of age, they were used for the vascular graft operations. Mice received an i.p. injection of fentanyl and midazolam (0.04 mg of fentanyl and $4 \mathrm{mg}$ of midazolam per $\mathrm{kg}$ of body weight) for sedation and were operated on under $1.5 \%$ isoflurane with $100 \%$ oxygen at a flow rate of $800 \mathrm{~mL} /$ minute $^{-1}$. A 10-mm incision was made from the manubrium 
to the chin of the mice, and the RCA was separated from surrounding tissue. Blood flow was temporarily cut off with silk sutures, and a small cut was made into the artery, allowing a 2-mm-long PTFE catheter (inner diameter, $0.3 \mathrm{~mm}$; external diameter, $0.6 \mathrm{~mm}$ ) to be placed inside the artery. The PTFE catheter was fixed in place using two silk sutures. The silk sutures that were cutting off the blood flow were removed, enabling blood to flow through the artery and catheter. The incision was sewn closed, and the surgical site was disinfected.

\section{Course of Vascular Graft Infection}

One week after vascular graft operation, mice were infected with $5 \times 10^{6} \mathrm{CFU} / \mathrm{mL}$ of $S$. aureus $\mathrm{LS} 1$ in $200 \mu \mathrm{L}$ of PBS via a lateral tail vein. As uninfected control, mice were injected with $200 \mu \mathrm{L}$ of PBS via a lateral tail vein. During the infection, mice were measured daily to follow-up weight and disease progression. If a weight loss of $15 \%$ occurred within 2 days, mice were euthanized. At 2, 7, 14, 21, or 42 days post infection (d.p.i.), mice were sacrificed, and organs (heart, kidneys, tibia, and brain), intracardiac blood, and catheter samples were collected in $2 \mathrm{~mL}$ of sterile PBS for colony-forming unit counts. The organs were homogenized and plated in various dilutions onto blood agar plates. The catheters were sonicated for 10 minutes and vortexed at high speed for 1 minute to ensure full removal of the biofilm from the catheter. This solution was then also plated in various dilutions onto blood agar plates.

\section{Vascular Graft Infection of Various S. aureus Strains}

Mice were infected with 8 different $S$. aureus strains, with varying capacity to form biofilm in vitro, 1 week after vascular graft operation. The strains and doses used are listed in Supplemental Table S1. At 14 d.p.i., mice were euthanized, and organs (heart, kidneys, tibia, and brain), intracardiac blood, and catheter samples were collected in $2 \mathrm{~mL}$ of sterile PBS for colony-forming unit counts. The organs and catheter were processed as mentioned above.

\section{MRI}

Three days after surgery (baseline) and 10 days after infection, mice were investigated by MRI to measure and monitor the blood flow through the LCA and RCA. Measurements were performed at 9.4 $\mathrm{T}$ on a BioSpec 94/20 USR small animal MRI system (Bruker BioSpin, Ettlingen, Germany) using ParaVision software version 5.1 (Bruker BioSpin, Ettlingen, Germany). A 35-mm-diameter mouse body quadrature volume coil (Rapid Biomedical, Rimpar, Germany) was used for data acquisition in a $1 \mathrm{~T} / \mathrm{m}$ gradient insert (BGS-6S, Bruker BioSpin, Ettlingen, Germany). Mice were anesthetized with inhalation anesthesia consisting of a $0.7 /$ 0.3 air/oxygen mixture with $1.5 \%$ to $2.5 \%$ isoflurane. Mice were positioned on a combined MR-PET bed and were connected to a small animal monitoring unit (SA Instruments, Inc., Stony Brook, NY) to measure respiration rate and ECG findings. The position inside the magnet bore was checked by using a self-gated cine FLASH sequence (repetition time/ echo time, 85.0/1.7 milliseconds; flip angle, $15^{\circ}$; field of view, $35 \times 35 \mathrm{~mm}^{2}$; section thickness, $0.5 \mathrm{~mm}$; acquisition matrix, $296 \times 296$ ). Subsequently, blood flow measurements were performed using a section-selective, balanced two-point velocity-encoded phase-contrast MRI sequence, which is based on a respiration and ECG-triggered FLASH gradient echo (Flowmap, Bruker BioSpin) (repetition time/echo time, $15.0 / 2.6$ milliseconds; flip angle, $30^{\circ}$; field of vision, $35 \times 35$ $\mathrm{mm}^{2}$; section thickness, $0.8 \mathrm{~mm}$; acquisition matrix, $296 \times$ 296; number of averages: 6) with three parallel sections (placed above and below the catheter as well as on site). After MRI measurements, the MR-PET mouse bed was transferred from the MRI scanner to the PET without changing the position of the mouse.

Analysis of velocity-encoded MRI data was performed in Matlab version R2014b (MathWorks, Inc., Natick, MA) as previously described. ${ }^{34}$

\section{PET}

Three days after surgery but before infection (baseline) and 10 days after infection with $S$. aureus or PBS injection, mice were subjected to PET using ${ }^{18} \mathrm{~F}$-fluorodeoxyglucose $\left({ }^{18} \mathrm{~F}-\mathrm{FDG}\right)$ to measure bacteria-induced inflammation.

After MRI acquisition, the animal bed was transferred into the PET scanner. PET studies were performed on a high-resolution small animal PET scanner (32-module quadHIDAC, Oxford Positron Systems Ltd., Oxford, UK) with uniform spatial resolution $(>1 \mathrm{~mm}$ full width at half maximum) over a large cylindrical field of view (165-mm diameter, 280-mm axial length). The PET data were reconstructed using one-pass list mode expectation maximization algorithm with resolution recovery. ${ }^{18}$ F-FDG PET images were acquired 70 to 85 minutes after intravenous injection of $10 \mathrm{MBq}{ }^{18} \mathrm{~F}-\mathrm{FDG}(150 \mu \mathrm{L})$. The MR images were used for anatomical co-registration with the PET images using a landmark-based approach by filling a contrast media/radiotracer mixture into canals with sphere-shaped cavities in the animal bed. The PET and MR images were then co-registered using the in-house developed image analysis software MEDgical version 0.7.3185 (European Institute for Molecular Imaging, Muenster, Germany).

To analyze the PET data, volumes of interest (VOIs) were defined based on MR images, with the examiner (S.H.) blinded to the PET imaging results. One VOI was drawn around the catheter in the RCA, and another VOI placed around the left carotid artery (LCA) was used as a reference. ${ }^{18}$ F-FDG uptake was expressed as standardized uptake values (SUVs), calculated by dividing the VOI radioactivity concentration by the injected activity multiplied by the body weight of the mouse [SUV $=(\mathrm{c})_{\mathrm{VoI}}$ injection dose $\times$ body weight]. Uptake ratios (SUV RCA/SUV LCA) were calculated. 


\section{Transmission Electron Microscopy}

Catheters were removed from mice 14 days d.p.i., and 4 catheters were analyzed using electron microscopy to visualize the biofilm formation. In brief, catheters were fixed in $4 \%$ formaldehyde and $0.25 \%$ glutaraldehyde in 100 $\mathrm{mmol} / \mathrm{L}$ sodium cacodylate buffer, $\mathrm{pH} 7.4$, at $4^{\circ} \mathrm{C}$. Afterward, samples were rinsed in PBS, dehydrated in ethanol up to $70 \%$, embedded in LR White medium (London Resin Company, London, UK), and polymerized using UV light according to the manufacturer's instructions. Ultrathin sections were cut on an ultramicrotome and collected on copper grids. For visualization of biofilms, ultrathin sections were incubated for 1 hour at room temperature with a lectin from Triticum vulgaris (wheat) (L 9640, Sigma-Aldrich, Munich, Germany) diluted 1:2000 in PBS. After 5 washing steps with PBS, sections were incubated with rabbit antibodies directed against the T. vulgaris lectin (T4144, SigmaAldrich) diluted 1:5000 in PBS followed by incubation for 1 hour with goat antibodies directed to rabbit immunoglobulins conjugated to 18-nm colloidal gold particles (Jackson ImmunoResearch Laboratories, West Grove, PA). Control experiments were performed in which the lectin was preincubated with $\mathrm{N}$-acetyl-D-glucosamine (A8625, SigmaAldrich). Finally, sections were rinsed with water and stained with $4 \%(\mathrm{w} / \mathrm{v})$ uranyl acetate. Electron micrographs were taken at $60 \mathrm{kV}$ with a Philips EM-410 transmission electron microscope (Philips, Eindhoven, the Netherlands).

\section{Confocal Laser Scanning Microscopy}

Four catheters isolated from mice 14 d.p.i., fixed in $4 \%$ formaldehyde, were longitudinally cut into two halves. After a permeabilization step for 10 minutes in PBS with $0.5 \%$ saponin and $0.1 \%$ Tween 20 , the catheters were incubated in blocking buffer consisting of 5\% bovine serum albumin (albumin fraction V from bovine serum, Merck, Darmstadt, Germany) and $300 \mathrm{mmol} / \mathrm{L}$ glycine (Sigma-Aldrich) in permeabilization buffer for 1 hour at room temperature. $S$. aureus was specifically labeled using a rabbit anti-S. aureus polyclonal IgG (generated by Squarix, Marl, Germany) diluted 1:200 in blocking buffer and incubated with the catheter overnight at $4^{\circ} \mathrm{C}$. After three washing steps in permeabilization buffer, the catheter were further incubated with a fluorescein isothiocyanate (FITC)-conjugated goat anti-rabbit IgG (Jackson Immunoresearch Laboratories) at 1:200 in blocking buffer for 1 hour at room temperature. Nucleic acid counterstaining was performed using DAPI (AppliChem, Darmstadt, Germany) at a concentration of $1 \mu \mathrm{g} / \mathrm{mL}$ for 10 minutes in blocking buffer.

Fluorescence images of stained catheters were acquired with a confocal laser scanning microscope (LSM780, Zeiss, Jena, Germany) using a $20 \times$ Plan-Apochromat objective (numerical aperture, 0.8; Zeiss) and ZEN software 2012 black edition (Zeiss). Fluorescence excitation and emission detection were conducted using a 405-nm laser diode and an adjustable bandpass filter set to 410 to $497 \mathrm{~nm}$ for DAPI and a 488-nm argon laser and a bandpass filter set at 493 to 634 $\mathrm{nm}$ for FITC. The pinhole was set to $34 \mu \mathrm{m}$. For spectral images, the emission was scanned from 495 to $691 \mathrm{~nm}$ with 8.9-nm spectral resolution. Linear unmixing with the Zeiss implemented algorithm was applied to the obtained spectral image by means of assigning each pixel spectrum to three different reference emission spectra. Reference spectrum for FITC was obtained from a positive control (FITC-labeled $S$. aureus only), reference spectrum for autofluorescence from a negative control (catheter incubated without anti-S. aureus and with secondary antibody only), and reference spectrum for background without fluorescence from the same image, each by choosing a region of interest displaying the respective fluorescence signal.

\section{FISH}

Four PTFE catheters were incubated with $S$. aureus LS1 in tryptic soy broth plus $0.25 \%$ glucose either in vitro for 24 hours with agitation or in vivo in the vascular graft model mentioned above for 4 weeks. The catheter samples were fixed and processed as described before. ${ }^{35}$ After embedding and cutting, the $2-\mu \mathrm{m}$ sections were enzymatically permeabilized and hybridized with FITC-labeled probe EUB $338,{ }^{36}$ complementary to the $16 \mathrm{~S}$ rRNA in most microorganisms and combined with Cy3-labeled S. aureusspecific probe SAU. ${ }^{37,38}$ In addition, fluorescence in situ hybridization (FISH) probe NON338 labeled with $\mathrm{Cy} 5^{39}$ was used to exclude unspecific binding. Furthermore, the samples were stained with DAPI. The hybridization mix was incubated on the catheter sections for 2 hours in a dark humid chamber. Examination of the FISH was performed using an epifluorescence microscope (Axioplan2, Carl Zeiss) with narrow band filter sets (AHF Analysentechnik, Tübingen, Germany).

\section{Enzyme-Linked Immunosorbent Assay}

From the mice infected with $S$. aureus LS1, blood was collected during the acute $(7$ d.p.i.) and the chronic (6 weeks post infection) phase of infection. Blood was allowed to clot at room temperature, followed by centrifugation for 5 minutes at $6093 \times g$, after which serum could be extracted. Serum levels of IL- $1 \beta$ and IL- 6 were determined by enzyme-linked immunosorbent assay according to the manufacturer's recommendations (RayBiotech, Norcross, GA).

\section{Ethics Statement}

All animal experiments were approved by the North RhineWestphalia Agency for Nature, Environment, and Consumer Protection (Landesamt für Natur, Umwelt und Verbraucherschutz Nordrhein-Westfalen-LANUV; ID 8402.04.2015.A298). 


\section{Statistical Analysis}

All statistical analyses were performed using GraphPad Prism software version 5 (GraphPad Software, La Jolla, CA). Comparison between two groups was performed with an unpaired $t$-test for parametric data and a $U$-test for nonparametric data. Comparison between more than two groups was performed using a one-way analysis of variance test. $P \leq 0.05$ was considered significant.

\section{Results}

\section{Course of Vascular Graft Infection}

We successfully set up the vascular graft infection model and were able to follow the infection progress up to 6 weeks. First, a 2-mm PTFE catheter was surgically placed into the RCA of CD1 mice. Three days after the operation, mice were noninvasively imaged using FDG-PET and MRI to evaluate baseline values of inflammation and blood flow velocities through the carotid arteries. This was followed by intravenous infection with $5 \times 10^{6} \mathrm{CFU} / \mathrm{ml}$ in $200 \mu \mathrm{L}$ of $S$. aureus LS1. The concentration was set in a way that the mice became ill but were eventually able to recover from the systemic infection. Choosing lower dosages led to the risk that the mice completely eliminate the infection before the bacteria are able to colonize the catheter (Supplemental Figure S1). At 10 d.p.i. mice again underwent FDG-PET and MRI to measure changes in inflammation and blood flow velocities through the carotid arteries due to the infection.

After infection, the mice were followed up for 6 weeks, and the course of the infection was divided into two phases. This has also been observed by Horst et $\mathrm{al}^{40}$ in a mouse model of chronic osteomyelitis. Directly after infection, the mice enter an acute phase throughout the first 2 weeks during which they showed clear signs of sepsis, such as weight loss, reduced mobility, and a high bacterial load in all analyzed organs (Figure 1A). This was accompanied by high levels of the inflammation markers IL- 6 and
IL-1 $\beta$ in the serum (Figure 1B). Infection was also often followed by septic emboli and abscess formation around the graft.

After 2 weeks the mice started recovering from sepsis and entered the chronic phase, which was characterized by a continuous reduction of bacteria in the kidneys but constant bacterial levels in the bones and on the catheter (Figure 1A). In addition, the levels of IL-1 $\beta$ in the serum had decreased significantly, yet the levels of IL-6 remained high (Figure 1B).

\section{In Vitro and in Vivo Biofilm Formation of Various Strains}

In vitro biofilm testing revealed that our positive control (S. epidermidis RP62A) had a very high level of biofilm formation to the polystyrene plate and that our negative control (S. carnosus TM300) had little to no biofilm formation (Figure 2A). S. aureus LS1 exhibited a relatively high level of biofilm formation in vitro. However, when analyzing the strains collected from patients and healthy individuals (nasal colonization), we observed only a few strong biofilm-forming strains, whereas most bacterial strains revealed basal levels of biofilm formation (Figure 2A). For comparison to our in vivo model, a selected number of strains were tested for their in vitro ability to form biofilm on PTFE catheters, and the results were comparable to the biofilm formation in the polystyrene plate (data not shown).

To test whether we could observe a correlation between biofilm-forming activity in vitro and the infection capacity in our in vivo model, four strong (S. aureus 36, 40, 62, and LS1) and four weak (S. aureus 31, 35, 44, and 46) biofilm formers were selected for infection in our vascular graft infection model (Figure 2B).

After in vivo infection with these eight different S. aureus strains, we first observed that the selected strains had varying levels of virulence in the mice and that different doses were necessary to induce colonization of the catheter (Supplemental Table S1). Some strains could be
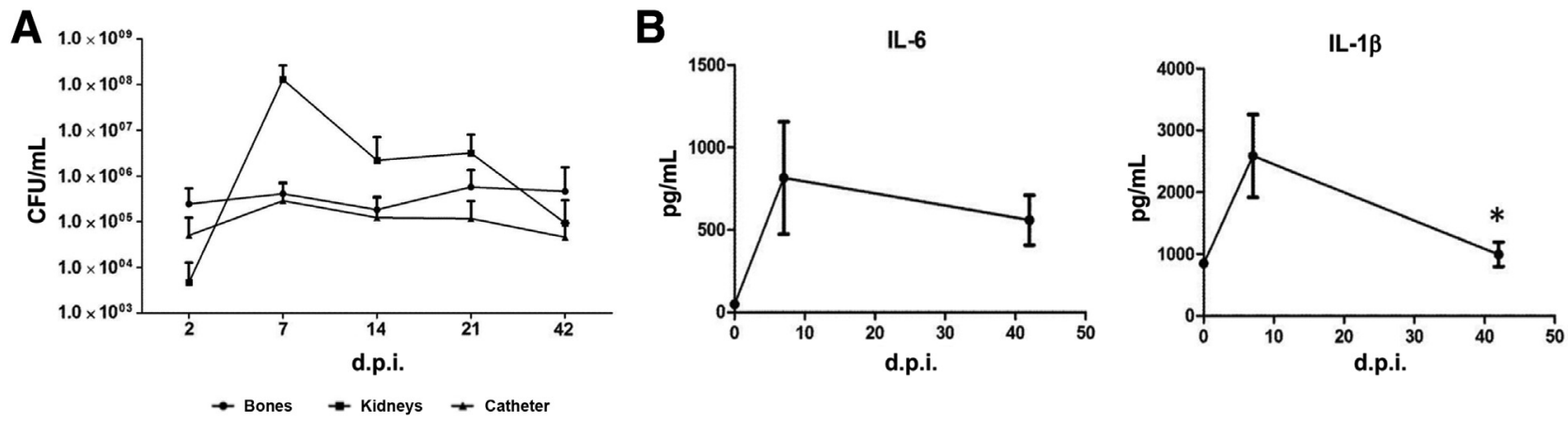

Figure 1 Follow-up of vascular graft infection with Staphylococcus aureus LS1. A: Mice were sacrificed 2, 7, 14, 21, and 42 days post infection (d.p.i.) and colony-forming unit (CFU) counts of bones, kidneys, and catheter were analyzed. B: Enzyme-linked immunosorbent assay on serum samples taken from infected mice 0, 7, and 42 d.p.i. Serum levels of IL-6 and IL-1 $\beta$ were measured. Data are expressed as means \pm SD. $n=10 .{ }^{*} P<0.05$. 

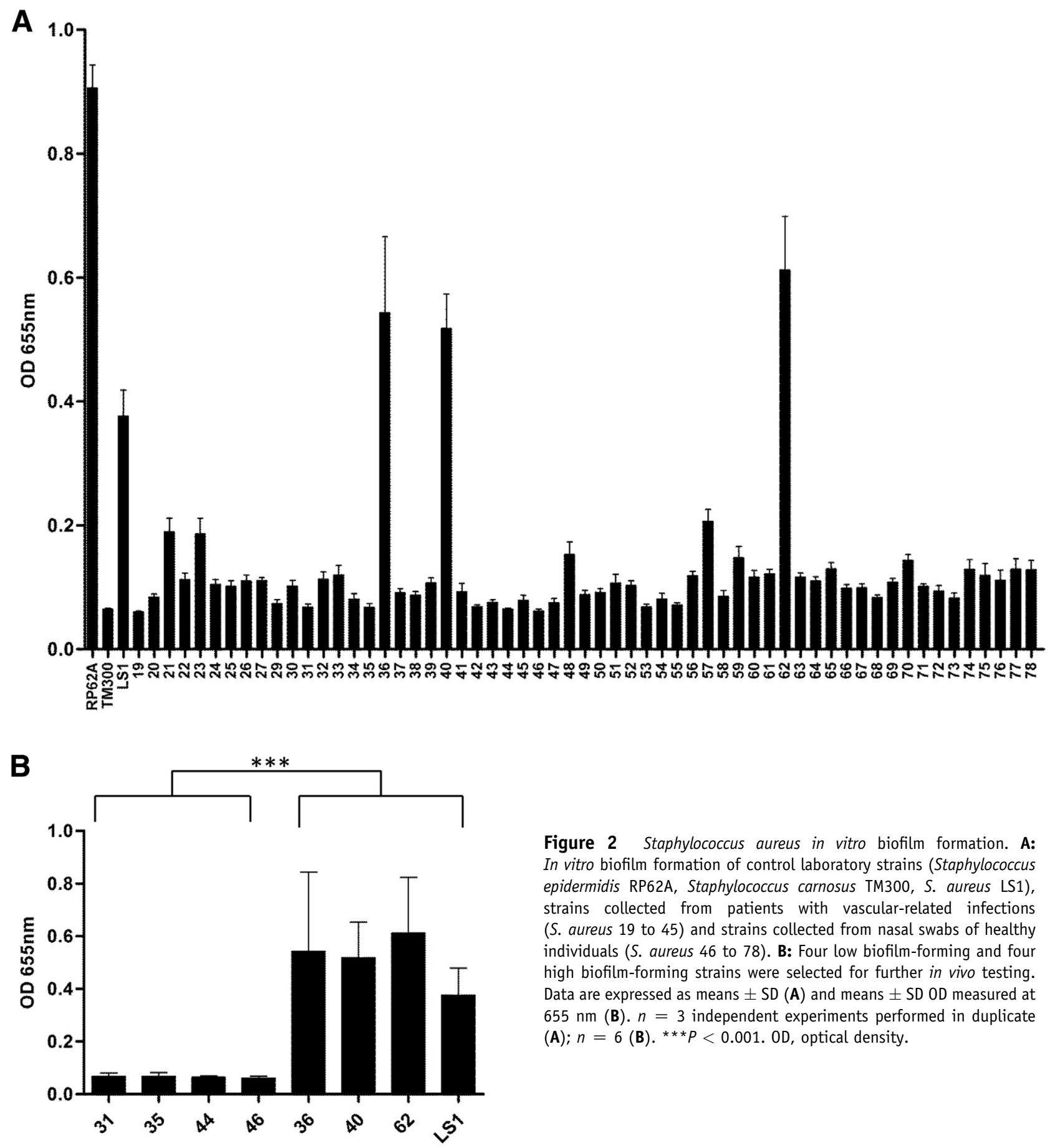

Figure 2 Staphylococcus aureus in vitro biofilm formation. A: In vitro biofilm formation of control laboratory strains (Staphylococcus epidermidis RP62A, Staphylococcus carnosus TM300, S. aureus LS1), strains collected from patients with vascular-related infections (S. aureus 19 to 45 ) and strains collected from nasal swabs of healthy individuals (S. aureus 46 to 78). B: Four low biofilm-forming and four high biofilm-forming strains were selected for further in vivo testing. Data are expressed as means \pm SD (A) and means \pm SD $0 D$ measured at $655 \mathrm{~nm}$ (B). $n=3$ independent experiments performed in duplicate (A); $n=6$ (B). ${ }^{* * *} P<0.001$. 0D, optical density.

characterized by high levels of infection in kidneys and bones accompanied by weight loss up to $10 \%$ to $20 \%$ of the initial body weight of the mice. Other strains had low infection levels in kidneys and bones and revealed little weight loss (Figure 3, A-C). However, despite this discrepancy in virulence, all selected strains, even those that revealed hardly any biofilm activity in vitro, colonized the intravascular catheter (Figure 3D). Furthermore, no correlation was found between the ability to form biofilm in vitro and the virulence of the strain in vivo.

\section{Noninvasive Follow-Up of Infection}

To assess changes in the blood flow velocity in the carotid arteries caused by the intravascular catheter and the development of bacterial biofilm, MRI was used. Blood flow velocities were measured 3 days after insertion of the catheter to establish a baseline value and then measured again 10 d.p.i. Figure $4 \mathrm{~A}$ illustrates a sagittal view of the RCA 3 days after the insertion of the catheter. MRI measurements revealed that the catheter did not cause any 
A

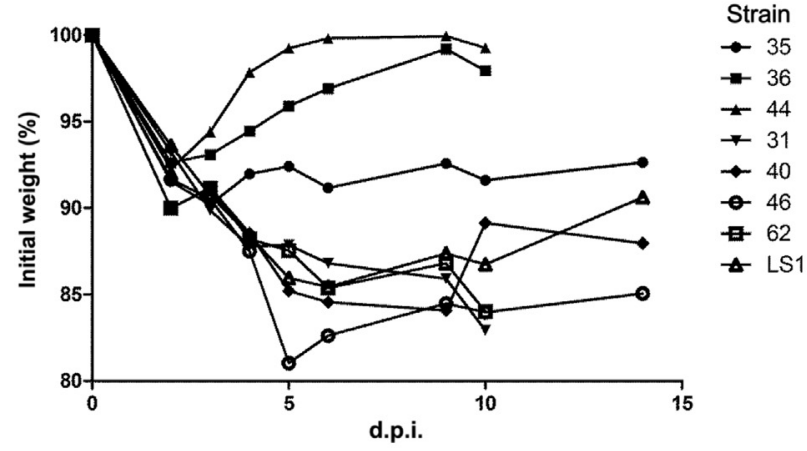

B Colonization of bones

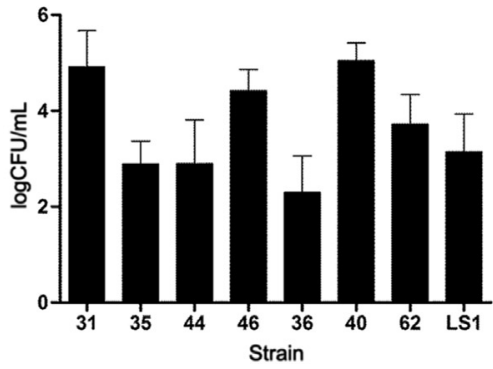

Colonization of kidneys

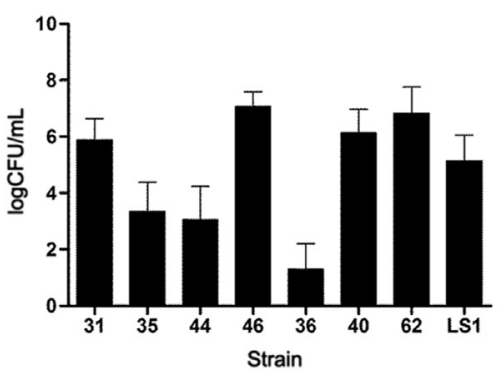

Figure 3 In vivo biofilm formation is a general characteristic of all tested Staphylococcus aureus strains. A: Percentage of initial body weight of mice during infection with various S. aureus strains. B-D: In vivo colonization of the femur and tibia (B), the kidneys (C), and the catheter (D) 14 days post infection (d.p.i.). Data are expressed as means \pm SEM. $n=10$.

D Colonization of catheter

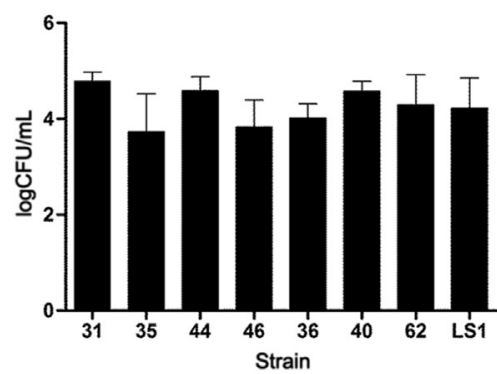

obstruction of the blood flow, although it altered the blood flow velocity by reducing the vessel diameter. In healthy unoperated mice, the blood flow velocity revealed no differences between the RCA and the LCA (flow velocities, 25 to $35 \mathrm{~cm} / \mathrm{s})$. After catheter placement, an increase of blood flow velocity (60 to $100 \mathrm{~cm} / \mathrm{s}$ ) in the RCA was observed compared with the LCA ( 25 to $35 \mathrm{~cm} / \mathrm{s}$ ), reflecting the decreased luminal diameter at the implantation site. MRI 10 d.p.i. reveals that the blood flow velocity in the RCA (with the inserted catheter) was significantly reduced by $86 \%$ compared with the baseline value (Figure 4B). In contrast, the blood flow velocity in the LCA, where no catheter was inserted, remained stable. In a control group, where mice received PBS instead of bacteria, the blood flow velocity through the catheter stayed on baseline level throughout the experiment (Figure 4B).

Noninvasive assessment of the course of localized infections in a three-dimensional, quantitative fashion is challenging. We used PET using the clinically established ${ }^{18} \mathrm{~F}-\mathrm{FDG}$ as a surrogate marker for inflammatory activity as a response to infection. Baseline measurements 3 days after insertion of the catheter revealed residual inflammatory response due to surgery-induced tissue damage. At 10 d.p.i. the catheter region presented with a significant increase in ${ }^{18} \mathrm{~F}$-FDG uptake compared with the baseline measurement. In contrast, the ${ }^{18} \mathrm{~F}-\mathrm{FDG}$ signal in the catheter region in the noninfected control mice did not increase. Actually, in the control mice we observed a tendency to a decreased ${ }^{18} \mathrm{~F}$-FDG uptake reflecting the recovery from the surgical intervention (Figure 4, C and D).

\section{Microscopic Characterization of the Biofilm Formation on the Vascular Graft}

Electron microscopy of the inner wall of the catheter 14 d.p.i. revealed microcolonies of bacteria surrounded by a matrix-like substance. Labeling with wheat germ lectin revealed that this matrix-like substance was made up of $\mathrm{N}$-acetyl-glucosamine, which is a key component of $S$. aureus biofilms (Figure 5A). Additional confocal laser scanning microscopy of immunofluorescent-stained $S$. aureus revealed evident signs of biofilm formation on the inner wall of the catheter (Figure 5B). Groups of FITClabeled bacteria were attached to the catheter wall and surrounded by murine host cells as revealed through DAPI labeling (Figure 5, B-E).

To establish FISH analysis to detect ribosomal RNA on the surface of vascular grafts and to get a better understanding of the differences between biofilm formation in vivo and in vitro, we compared biofilms that were grown on a catheter in vitro to those in our mouse infection model. Applying FISH on the in vitro catheters revealed multilayer biofilms formed outside the material, with a high number of bacteria revealing bright FISH signals (Figure 6). In none of the samples did the NON338 $8_{\mathrm{Cy} 5}$ reveal unspecific signals with any bacteria (data not shown).

In vivo biofilms were located in the lumen of the catheters showing weak FISH signal intensity in 3 of 4 cases (Figure 7). The lumina of all catheters were infiltrated with a high amount of blood cells. In one sample the in vivo grown biofilms had FISH signal intensity comparable to the in vitro biofilms 
A

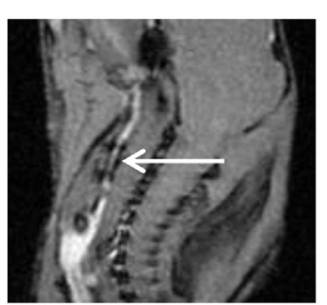

B

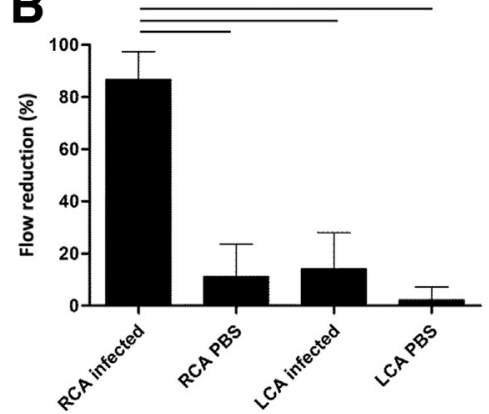

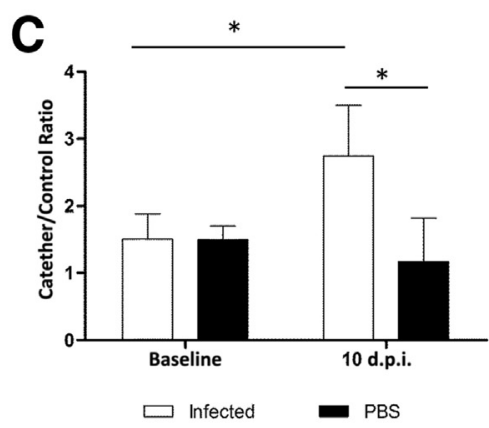

S. aureus
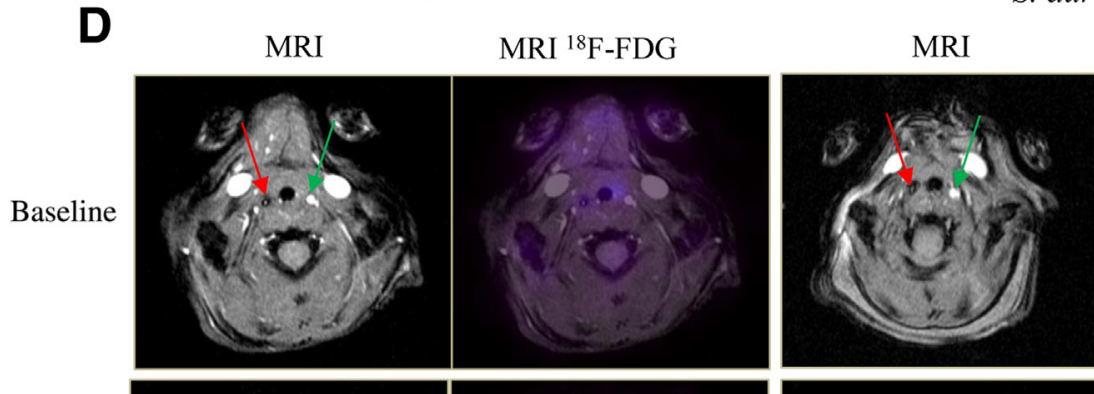

MRI ${ }^{18} \mathrm{~F}-\mathrm{FDG}$
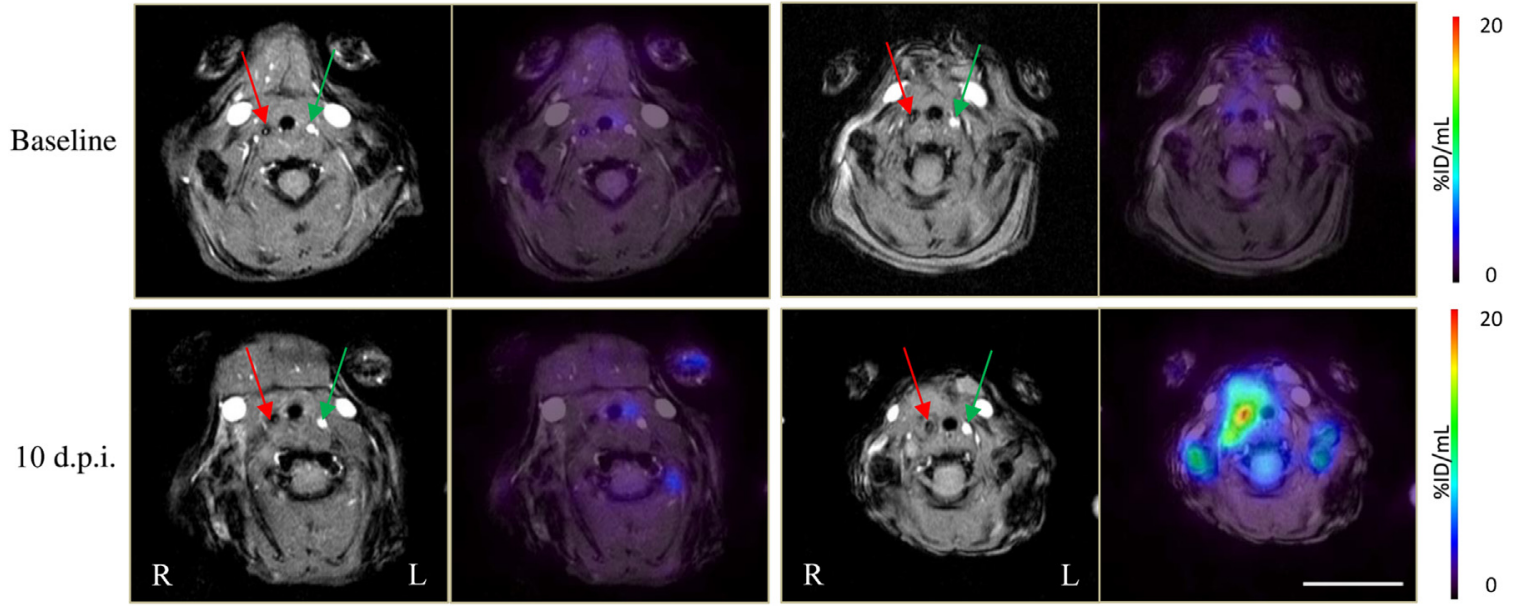

Figure 4 Noninvasive imaging of in vivo Staphylococcus aureus LS1 vascular graft infection. A: Sagittal magnetic resonance imaging (MRI) [fast low-angle shot (FLASH)] of the right carotid artery (RCA). The inserted catheter is marked with a white arrow. B: Percentage of flow reduction 10 days post infection (d.p.i.) through the RCA (with catheter) and the left carotid artery (LCA) (without catheter) compared with before infection (baseline). C: Quantification of ${ }^{18} \mathrm{~F}$-fluordeoxyglucose $\left({ }^{18} \mathrm{~F}\right.$-FDG) uptake. D: MRI (FLASH) showing the location of the RCA (red arrows) and the LCA (green arrows). Combined MR and ${ }^{18} \mathrm{~F}$-FDG images reveal increased uptake of the inflammation marker ${ }^{18}$ F-FDG in the RCA 10 days after $S$. aureus infection. Data are expressed as the mean standardized uptake values in the RCA (with catheter) compared with the LCA (without catheter) before and after infection or phosphate-buffered saline (PBS) control respectively $(\mathbf{A}-\mathbf{C})$ and as means \pm SD (D). $n=6 .{ }^{*} P<0.05,{ }^{* *} P<0.001$. Scale bar $=1 \mathrm{~cm}$ (D).

(Supplemental Figure S2). In both in vitro and in vivo models, bacteria hybridizing with EUB338 $8_{\text {FITC }}$ were also detected by $\mathrm{SAU}_{\mathrm{cy} 3}$, proving infection with $S$. aureus exclusively.

\section{Discussion}

Vascular graft infections are very serious complications with a high risk of mortality. Diagnosis of these infections is difficult because hitherto no bacteria-specific imaging tools are clinically available and these infections are usually accompanied by unspecific symptoms. Of note, there are currently no effective treatment strategies other than removal of the infected device. This is a severe complication, considering most of these patients are already in a vulnerable health condition. Fully understanding the underlying pathogenesis of these infections is crucial to find early diagnostic techniques and reliable long-lasting treatment strategies. This can only be achieved with the help of a representable animal model that closely reflects all stages of biofilm formation in the clinical situation. Because this is currently lacking, this project aimed to set up an appropriate murine model by implanting a PTFE catheter, a polymer material often used for vascular grafts, ${ }^{32}$ inside the carotid artery of mice followed by intravenous infection with $S$. aureus. In our model, bacteria were able to form a strong, long-term biofilm layer on the implant, even under the stress of high blood flow in the carotid arteries and under the pressure of the host immune system that the bacteria encounter in the vascular system.

The model was tested with 8 different $S$. aureus strains, all originating from diverse sources: one laboratory strain originating from a mouse infection, five strains collected from patients with vascular-related infections, and two strains collected from nasal cavities of healthy individuals. In vitro these strains had a variable ability to form biofilm 

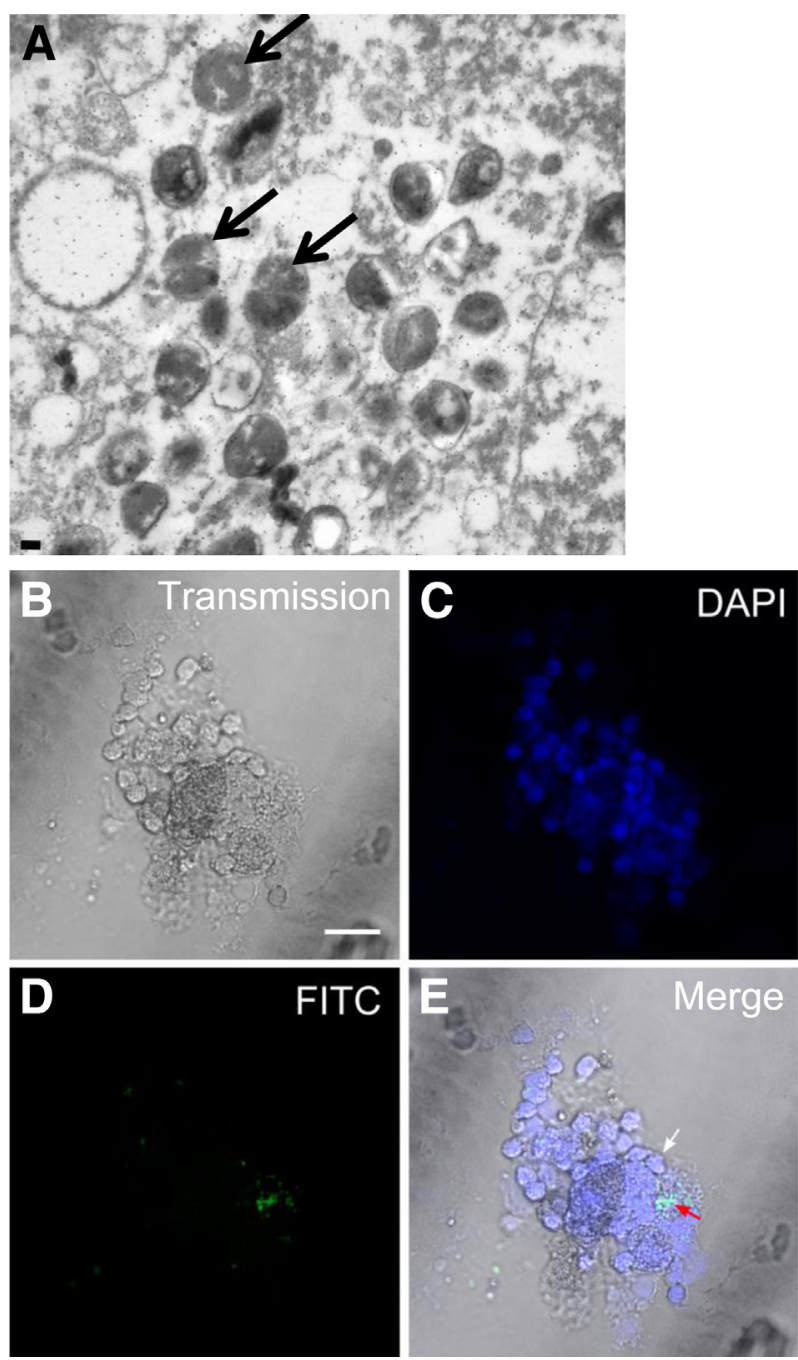

Figure 5 Microscopic analysis of in vivo grown Staphylococcus aureus LS1 biofilm. A: Transmission electron microscopy of the inner wall of a catheter 14 days post infection (d.p.i.) and immunogold labeling of wheat germ lectin, which was bound to $\mathrm{N}$-acetyl-glucosamine (a key component of biofilm matrix). Bacteria are marked with black arrows. The immunogold labeling has a grain-like appearance on the micrograph. B-E: Confocal laser scanning microscopy of inner wall of catheter 14 d.p.i. DAPI staining reveals nuclei of murine host cells (C, white arrow in $\mathbf{E}$ ), and fluorescein isothiocyanate (FITC) labeling of $S$. aureus with a specific antibody reveals the specific location of the bacteria (D, red arrow in E). Scale bars: $200 \mathrm{~nm}$ (A); $20 \mu \mathrm{m}(\mathbf{B}-\mathbf{E})$.

with only four of the strains being good biofilm formers, whereas the other four only had a basal ability to form biofilm. However, when put into a stressful in vivo situation, all these strains formed thick biofilm layers on the vascular prosthesis, implying that the bacteria quickly adapt to their new environment and establish a biofilm-associated infection. The formation of biofilm was verified ex vivo by various microscopic tools, all of which had consistent biofilm layers. These results indicate that the colonization and biofilm-associated vascular graft infection is a general characteristic of all tested $S$. aureus isolates and is not limited to high biofilm formers in vitro. The clinical manifestation of infection observed in mice was very similar to that in humans. Infection was often followed by septic emboli, abscess formation around the graft, and a systemic sepsis. ${ }^{41}$ After approximately 2 weeks the mice recovered from the sepsis, but even after recovering from a systemic infection, the biofilm on the graft remained, acting as a longterm reservoir for metastatic infections.

Instead of placing the graft subcutaneously, as performed in previous preclinical research models, ${ }^{42-44}$ we placed it inside the carotid artery, a surrounding that meets much more the environmental conditions of vascular prosthetics in humans (eg, high blood flow, direct contact to the blood immune system, and very different immunologic conditions
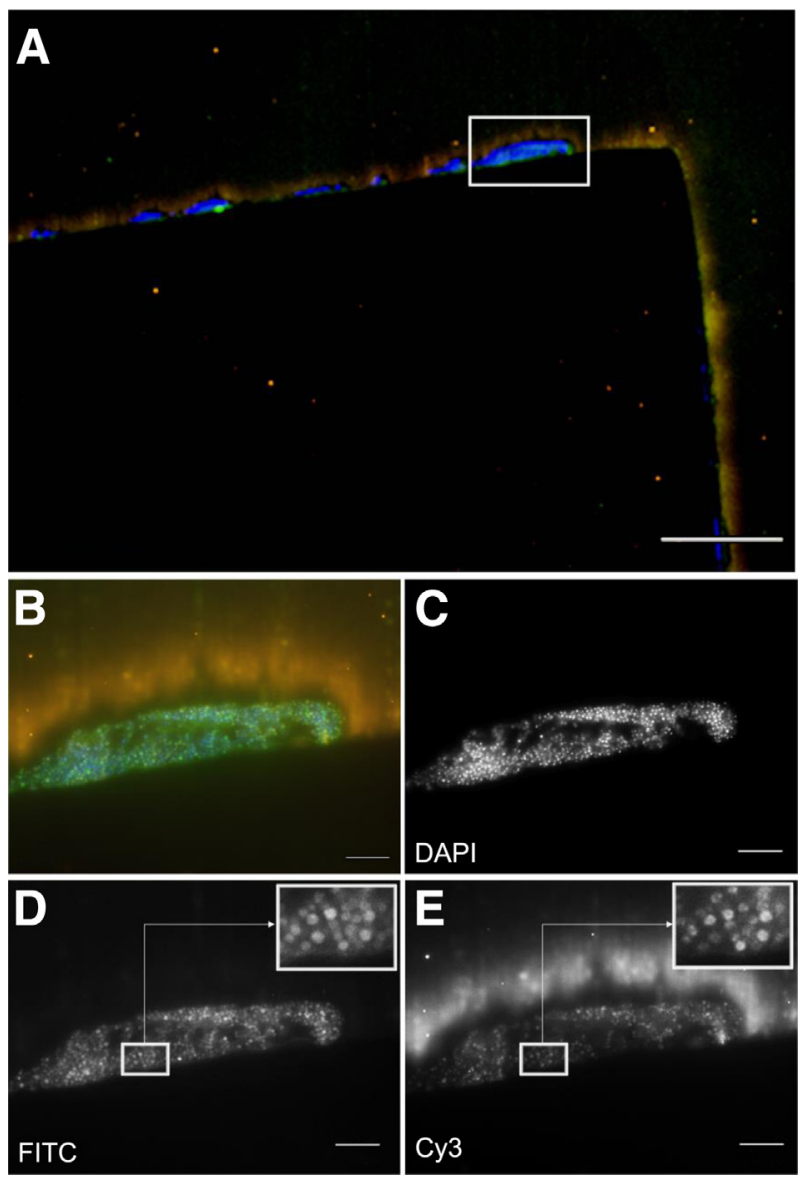

Figure 6 Fluorescence in situ hybridization (FISH) of in vitro grown Staphylococcus aureus LS1 biofilm on a polytetrafluoroethylene catheter. The section was hybridized with the pan-bacterial probe EUB338 $8_{\text {FITC }}$ (green), S. aureus-specific probe $\mathrm{SAU}_{\mathrm{Cy} 3}$ (yellow), nonsense probe NON338 (magenta), and nucleic acid stain DAPI (blue). A: Overview with the biofilm located on the outside of the catheter. Boxed area is shown at higher magnification in B-E. B-E: Demonstration of the different fluorescence signals within a detail showing multilayer cocci with strong fluorescence signals. Boxed areas are shown at higher magnification in the insets. B: Merged image of all channels, showing multilayer cocci with strong FISH signals. C-E: Black and white images of the single fluorescence channels showing nucleic acid stain DAPI (C), pan-bacterial probe EUB338 $8_{\text {FITC }}$ (D), and $S$. aureus - specific $\mathrm{SAU}_{\mathrm{Cy} 3}$ signals (E). Note that all bacteria stained by EUB338 are also showing signals with probe $\mathrm{SAU}_{\mathrm{Cy} 3}$. Scale bars: $100 \mu \mathrm{m}$ (A); $10 \mu \mathrm{m}(\mathbf{B}-\mathbf{E})$. 

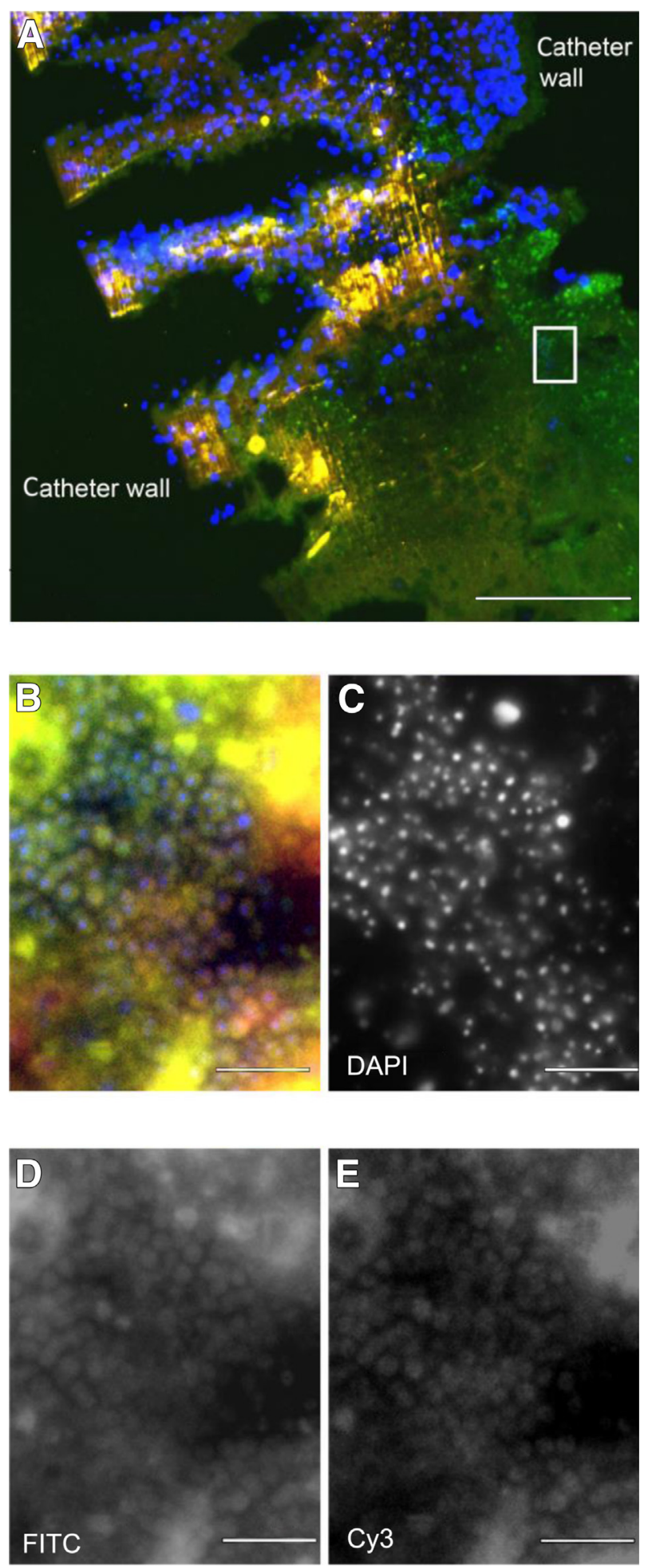

Figure 7 Fluorescence in situ hybridization (FISH) of catheter sections infected by Staphylococcus aureus LS1 in an in vivo mouse model. FISH using the pan-bacterial probe EUB338FITC (green), S. aureus-specific probe SAUCy3 (orange/yellow), the nonsense probe NON338 (data not shown), and unspecific nucleic acid stain DAPI (blue). A: Overview of the lumen of the catheter filled with a matrix and host blood cells. Boxed area is shown at higher magnification in panels $\mathbf{B}-\mathbf{E}$. B: At higher magnification, a microcolony is visible. C: DAPI shows the single bacteria. D and E: Only weak FISH signals were with the pan-bacterial (D) and S. aureusspecific probe (E). Scale bars: $100 \mu \mathrm{m}(\mathbf{A}) ; 5 \mu \mathrm{m}(\mathbf{B}-\mathbf{E})$. compared with inside a subcutaneous pocket). This orthotopic graft placement allows for studying the virulence factors that the bacteria need to activate to overcome the pressure of the high blood flow and stressful immune system, enabling them to form these chronic infections. By placing the graft inside the vascular system, we are also able to study the possible effect of the activated endothelium on the infection process, which is being ignored in existing subcutaneous graft models. Thus, this infection model, by closely mimicking the environmental conditions of the clinical situation, has a high potential for the investigation of the multiple strategies and adaptation mechanisms that the bacteria need to survive on vascular (graft) surfaces.

Furthermore, FISH analysis of both in vivo and in vitro catheters confirmed that multilayer homogenous biofilms were formed in all samples investigated. In the in vivo model, the bacterial communities were predominantly found at the blood-graft contact site (ie, the luminal surface of the catheters). Compared with the in vitro biofilms, pronounced differences were seen in the structure of the in vivo grown biofilms with a high number of host cells merged with matrix and bacteria. In addition, the number of FISHpositive bacteria and FISH signal intensity differed, being lower in the catheters from the in vivo model. The low FISH signal of the bacteria in vivo could be attributable to a stationary or resting mode, possibly resulting in a higher tolerance toward antibiotic treatment in a clinical situation. Furthermore, bacteria in biofilms are less sensitive to the immune system because of the quiescent mode of growth in these structures. These results further support the relevance of our in vivo vascular graft model, which more closely represents the in vivo situation, with the immune system and blood flow influencing the bacterial metabolism. This contrasts previous models where the bacteria are inoculated straight onto the surface of the graft or inoculated in vitro, which could result in very different bacterial reactions. ${ }^{24-26}$

Our model not only allows us to study the underlying bacterial pathomechanisms but also provides, in parallel, the possibility of investigating the host immune response. IL-1 $\beta$ and IL-6 are known to be crucial mediators of staphylococcal disease, and in our model we measured an elevated expression of these cytokines during infection. ${ }^{45,46}$ In line with our results, continuously elevated levels of IL-6 expression have been reported previously to play an important role in chronic $S$. aureus biofilm infections. ${ }^{47}$ Therefore, our infection model provides a basis for studying the host immune responses, which opens up the possibility to study novel immune-oriented therapies. Moreover, having established this model in mice offers the possibility of using the vast array of genetically manipulated and humanized mice, which can lead to a much more in-depth understanding of the host's role during chronic infections.

Because there is always variability in infection among different mice, imaging provides a way to monitor the disease in the single mouse from baseline onward. We used FDG-PET as a clinically established tool to image 
inflammation to assess the course of graft infection. FDGPET does not specifically image bacteria but instead images cellular FDG uptake, corresponding to the degree of glucose transport and metabolism, which is upregulated in activated inflammatory cells. In our study, by applying FDG-PET, we found the increase of inflammatory activity at the vascular graft in contrast to the contralateral side and carotid arteries in noninfected control mice. In addition to FDG-PET, MRI was performed, which revealed that the blood flow velocity was decreased through the catheter because of the infection and biofilm formation. Thus, the combined application of FDG-PET and MRI is a powerful strategy to monitor the course of bacterial infection noninvasively in our novel mouse model. This strategy offers the possibility of longitudinally quantifying the effectiveness of new therapies. In addition, given the human-like nature of the graft infection, this model should provide a very good basis for studying new diagnostic strategies (eg, by bacteria-specific imaging).

Despite research being performed so far on in vitro systems, animal models, and clinical samples, we are still lacking complete knowledge of the pathogenesis of foreign material-related infections because of inaccurate model systems that do not reflect the whole infection process. Our murine model takes all steps of the pathogenesis into account and has already revealed that the ability to form chronic biofilm infections is an ability of all clinical $S$. aureus strains, regardless of their in vitro biofilm activity or their level of virulence in the host. The major advantage of this model is that it is completely endovascular, meaning that the catheter is inside the artery and the bacteria are delivered to the catheter hematogenously via the blood flow. This allows us to take important factors into account, such as blood flow and the shear stress caused by the blood flow, which is said to have a significant effect on the formation of biofilm. ${ }^{48}$ This model also enables us to study the interrelationship between biofilm and thrombus formation, which has already been found to play an important role in central venous catheters and endocarditis. ${ }^{49,50}$ In addition, the influx of host immune cells can be very different, depending on where the catheter is placed, and can therefore have an effect on the host immune response. Thus, our novel model provides a solid platform for microbiological and immunologic experiments that could provide crucial insights into the pathogenesis and the diagnosis and treatment of these devastating infections.

\section{Acknowledgments}

We thank Desiree Block, Brigitte Schuhen, Michaela Brück, and Kornelia Parusel for excellent assistance in the processing of experiments and their help with scientific discussions; Dirk Reinhardt for help with the operational procedures; and Karin Schlattmann and Roman Priebe for excellent technical help.

\section{Supplemental Data}

Supplemental material for this article can be found at http://dx.doi.org/10.1016/j.ajpath.2016.10.005.

\section{References}

1. Hasse B, Husmann L, Zinkernagel A, Weber R, Lachat M, Mayer D: Vascular graft infections. Swiss Med Wkly 2013, 143:w13754

2. Erb S, Sidler JA, Elzi L, Gurke L, Battegay M, Widmer AF, Weisser M: Surgical and antimicrobial treatment of prosthetic vascular graft infections at different surgical sites: a retrospective study of treatment outcomes. PLoS One 2014, 9:e112947

3. Legout L, D'Elia PV, Sarraz-Bournet B, Haulon S, Meybeck A, Senneville E, Leroy O: Diagnosis and management of prosthetic vascular graft infections. Med Maladies Infect 2012, 42:102-109

4. Sousa JV, Antunes L, Mendes C, Marinho A, Gonçalves A, Gonçalves O, Matos A: Prosthetic vascular graft infections: a center experience. Angiol Cirurgia Vasc 2014, 10:52-57

5. Otto M: Staphylococcal biofilms. Curr Top Microbiol Immunol 2008, 322:207-228

6. Archer NK, Mazaitis MJ, Costerton JW, Leid JG, Powers ME, Shirtliff ME: Staphylococcus aureus biofilms: properties, regulation and roles in human disease. Virulence 2011, 2:445-459

7. McCarthy H, Rudkin JK, Black NS, Gallagher L, O'Neill E, O'Gara JP: Methicillin resistance and the biofilm phenotype in Staphylococcus aureus. Front Cell Infect Microbiol 2015, 5:1

8. Singh R, Ray P, Das A, Sharma M: Penetration of antibiotics through Staphylococcus aureus and Staphylococcus epidermidis biofilms. J Antimicrob Chemother 2010, 65:1955-1958

9. Ceri H, Olson ME, Stremick C, Read RR, Morck D, Buret A: The calgary biofilm device: new technology for rapid determination of antibiotic susceptibilities of bacterial biofilms. J Clin Microbiol 1999, 37:1771-1776

10. Penesyan A, Gillings M, Paulsen IT: Antibiotic discovery: combatting bacterial resistance in cells and in biofilm communities. Molecules 2015, 20:5286-5298

11. Bisdas T, Beckmann E, Marsch G, Burgwitz K, Wilhelmi M, Kuehn C, Haverich A, Teebken OE: Prevention of vascular graft infections with antibiotic graft impregnation prior to implantation: in vitro comparison between daptomycin, rifampin and nebacetin. Eur J Vasc Endovasc Surg 2012, 43:448-456

12. Cirioni O, Mocchegiani F, Ghiselli R, Silvestri C, Gabrielli E, Marchionni E, Orlando F, Nicolini D, Risaliti A, Giacometti A: Daptomycin and rifampin alone and in combination prevent vascular graft biofilm formation and emergence of antibiotic resistance in a subcutaneous rat pouch model of staphylococcal infection. Eur J Vasc Endovasc Surg 2010, 40:817-822

13. Schneider F, O'Connor S, Becquemin JP: Efficacy of collagen silvercoated polyester and Rifampin-soaked vascular grafts to resist infection from MRSA and Escherichia coli in a dog model. Ann Vasc Surg 2008, 22:815-821

14. Kuehn C, Graf K, Mashaqi B, Pichlmaier M, Heuer W, Hilfiker A, Stiesch M, Chaberny IF, Haverich A: Prevention of early vascular graft infection using regional antibiotic release. J Surg Res 2010, 164 : e185-e191

15. Keeling WB, Myers AR, Stone PA, Heller L, Widen R, Back MR, Johnson BL, Bandyk DF, Shames ML: Regional antibiotic delivery for the treatment of experimental prosthetic graft infections. J Surg Res 2009, 157:223-226

16. Lehar SM, Pillow T, Xu M, Staben L, Kajihara KK, Vandlen R, DePalatis L, Raab H, Hazenbos WL, Morisaki JH, Kim J, Park S, Darwish M, Lee B, Hernandez H, Loyet KM, Lupardus P, Fong R, Yan D, Chalouni C, Luis E, Khalfin Y, Plise E, Cheong J, Lyssikatos JP, Strandh M, Koefoed K, Andersen PS, Flygare JA, 
Tan MW, Brown EJ, Mariathasan S: Novel antibody-antibiotic conjugate eliminates intracellular S. aureus. Nature 2015, 527:323-328

17. Merritt JH, Kadouri DE, O'Toole GA: Growing and analyzing static biofilms. Curr Protoc Microbiol 2005, Chapter 1:Unit-1B.1

18. Ghigo JM: Natural conjugative plasmids induce bacterial biofilm development. Nature 2001, 412:442-445

19. Woods J, Boegli L, Kirker KR, Agostinho AM, Durch AM, Delancey Pulcini E, Stewart PS, James GA: Development and application of a polymicrobial, in vitro, wound biofilm model. J Appl Microbiol 2012, 112:998-1006

20. Benoit MR, Conant CG, Ionescu-Zanetti C, Schwartz M, Matin A: New device for high-throughput viability screening of flow biofilms. Appl Environ Microbiol 2010, 76:4136-4142

21. Bjarnsholt T, Alhede M, Alhede M, Eickhardt-Sørensen SR, Moser C, Kühl M, Østrup Jensen P, Høiby N: The in vivo biofilm. Trends Microbiol 2013, 21:466-474

22. Tuchscherr L, Bischoff M, Lattar SM, Llana MN, Pförtner H, Niemann S, Geraci J, Van de Vyver H, Fraunholz MJ, Cheung AL, Herrmann M, Völker U, Sordelli DO, Peters G, Löffler B: Sigma factor SigB is crucial to mediate Staphylococcus aureus adaptation during chronic infections. PLoS Pathog 2015, 11:e1004870

23. Schmiedel D, Kikhney J, Masseck J, Rojas Mencias PD, Schulze J, Petrich A, Thomas A, Henrich W, Moter A: Fluorescence in situ hybridization for identification of microorganisms in acute chorioamnionitis. Clin Microbiol Infect 2014, 9:O538-O541

24. Arya R, Ravikumar R, Santhosh RS, Princy SA: SarA based novel therapeutic candidate against Staphylococcus aureus associated with vascular graft infections. Front Microbiol 2015, 6:416

25. De Cremer K, Delattin N, De Brucker K, Peeters A, Kucharíková S, Gerits E, Verstraeten N, Michiels J, Van Dijck P, Cammue BPA, Thevissen K: Oral administration of the broad-spectrum antibiofilm compound Toremifene inhibits Candida albicans and Staphylococcus aureus biofilm formation in vivo. Antimicrob Agents Chemother 2014, 58:7606-7610

26. Giacometti A, Cirioni O, Ghiselli R, Orlando F, D'Amato G, Kamysz W, Mocchegiani F, Sisti V, Silvestri C, Łukasiak J, Rocchi M, Saba V, Scalise G: Temporin A soaking in combination with intraperitoneal Linezolid prevents vascular graft infection in a subcutaneous rat pouch model of infection with Staphylococcus epidermidis with intermediate resistance to glycopeptides. Antimicrob Agents Chemother 2004, 48:3162-3164

27. Gao H, Sandermann J, Prag J, Lund L, Lindholt JS: Prevention of primary vascular graft infection with silver-coated polyester graft in a porcine model. Eur J Vasc Endovasc Surg 2010, 39:472-477

28. Langerhuus SN, Tønnesen EK, Jensen KH, Damgaard BM, Heegaard PMH, Halekoh U, Lauridsen C: Brief report: biomarkers of aortic vascular prosthetic graft infection in a porcine model with Staphylococcus aureus. Eur J Clin Microbiol Infect Dis 2010, 29: $1453-1456$

29. Javerliat I, Goëau-Brissonnière O, Sivadon-Tardy V, Coggia M, Gaillard JL: Prevention of Staphylococcus aureus graft infection by a new gelatin-sealed vascular graft prebonded with antibiotics. J Vasc Surg 2007, 46:1026-1031

30. Schmacht D, Armstrong P, Johnson B, Pierre K, Back M, Honeyman A, Cuthbertson D, Bandyk D: Graft infectivity of rifampin and silver-bonded polyester grafts to MRSA contamination. Vasc Endovasc Surg 2005, 39:411-420

31. Schultz LD, Ishikawa F, Greiner DL: Humanized mice in translational biomedical research. Nat Rev Immunol 2007, 7:118-130

32. Kapadia MR, Popowich DA, Kibbe MR: Modified prosthetic vascular conduits. Circulation 2008, 117:1873-1882

33. Bremell T, Abdelnour A, Tarkowski A: Histopathological and serological progression of experimental Staphylococcus aureus arthritis. Infect Immun 1992, 60:2976-2985

34. Bovenkamp PR, Brix T, Lindemann F, Holtmeier R, Abdurrachim D, Kuhlmann MT, Strijkers GJ, Stypmann J, Hinrichs KH, Hoerr V: Velocity mapping of the aortic flow at $9.4 \mathrm{~T}$ in healthy mice and mice with induced heart failure using time-resolved three-dimensional phase-contrast MRI (4D PC MRI). MAGMA 2015, 28:315-327

35. Moter A, Leist G, Rudolph R, Schrank K, Choi BK, Wagner M, Göbel UB: Fluorescence in situ hybridization shows spatial distribution of as yet uncultured treponemes in biopsies from digital dermatitis lesions. Microbiology 1998, 144:2459-2467

36. Amann RI, Binder BJ, Olson RJ, Chisholm SW, Devereux R, Stahl DA: Combination of 16S rRNA-targeted oligonucleotide probes with flow cytometry for analyzing mixed microbial populations. Appl Environ Microbiol 1990, 56:1919-1925

37. Kempf VAJ, Trebesius K, Autenrieth IB: Fluorescent in situ hybridization allows rapid identification of microorganisms in blood cultures. J Clin Microbiol 2000, 38:830-838

38. Gescher DM, Kovacevic D, Schmiedel D, Siemoneit S, Mallmann C, Halle E, Göbel UB, Moter A: Fluorescence in situ hybridisation (FISH) accelerates identification of Gram-positive cocci in positive blood cultures. Int J Antimicrob Agents 2008, 32: Suppl 1:S51-S59

39. Wallner G, Amann R, Beisker W: Optimizing fluorescent in situ hybridization with rRNA-targeted oligonucleotide probes for flow cytometric identification of microorganisms. Cytometry 1993, 14: 136-143

40. Horst SA, Hoerr V, Beineke A, Kreis C, Tuchscherr L, Kalinka J, Lehne S, Schleicher I, Köhler G, Fuchs T, Raschke MJ, Rohde M, Peters G, Faber C, Löffler B, Medina E: A novel mouse model of Staphylococcus aureus chronic osteomyelitis that closely mimics the human infection - an integrated view of disease pathogenesis. Am J Pathol 2012, 181:1206-1214

41. Young MH, Upchurch GR Jr, Malani PN: Vascular graft infections. Infect Dis Clin North Am 2012, 26:41-56

42. Lorenz U, Schäfer T, Ohlsen K, Tiurbe GC, Bühler C, Germer CT, Kellersmann R: In vivo detection of Staphylococcus aureus in biofilm on vascular prostheses using non-invasive biophotonic imaging. Eur J Vasc Endovasc Surg 2011, 41:68-75

43. Kristian SA, Golda T, Ferracin F, Cramton SE, Neumeister B, Peschel A, Götz F, Landmann R: The ability of biofilm formation does not influence virulence of Staphylococcus aureus and host response in a mouse tissue cage infection model. Microb Pathog 2004, 36:237-245

44. Turgut H, Sacar S, Kaleli I, Sacar M, Goksin I, Toprak S, Asan A, Cevahir N, Tekin K, Baltalarli A: Systemic and local antibiotic prophylaxis in the prevention of Staphylococcus epidermidis graft infection. BMC Infect Dis 2005, 5:91

45. Megyeri K, Mándi Y, Degré M, Rosztóczy I: Induction of cytokine production by different staphylococcal strains. Cytokine 2002, 19: 206-212

46. Wang JE, Jørgensen PF, Almlöf M, Thiemermann C, Foster SJ, Aasen AO, Solberg R: Peptidoglycan and lipoteichoic acid from Staphylococcus aureus induce tumor necrosis factor alpha, interleukin 6 (IL-6), and IL-10 production in both T cells and monocytes in a human whole blood model. Infect Immun 2000, 68: 3965-3970

47. Prabhakara R, Harro JM, Leid JG, Harris M, Shirtliff ME: Murine Immune response to a chronic Staphylococcus aureus biofilm infection. Infect Immun 2011, 79:1789-1796

48. Pavithra D, Doble M: Biofilm formation, bacterial adhesion and host response on polymeric implants - issues and prevention. Biomed Mater 2008, 3:1-13

49. Smith RS, Zhang Z, Bouchard M, Li J, Lapp HS, Brotske GR, Lucchino DL, Weaver D, Roth LA, Coury A, Biggerstaff J, Sukavaneshvar S, Langer R, Loose C: Vascular catheters with a nonleaching poly-sulfobetaine surface modification reduce thrombus formation and microbial attachment. Sci Transl Med 2012, 4: $153 \mathrm{ra} 132$

50. Donlan RM, Costerton JW: Biofilms: survival mechanisms of clinically relevant microorganisms. Clin Microbiol Rev 2002, 15: 167-193 